\title{
COMPARISON OF EFFECTS OF DIFFERENT ANTIDOTES ON TABUN-INDUCED COGNITIVE IMPAIRMENT IN RATS USING WATER MAZE
}

\author{
Gabriela Kunešová, Jiři Kassa
}

University of Defence, Faculty of Military Health Sciences, Hradec Králové, Czech Republic: Department of Toxicology

Summary: In the past, scientists focused on the development of antidotes (mainly anticholinergics in combination with reactivators of inhibited acetylcholinesterase - oximes) to increase the number of surviving nerve agent-intoxicated individuals. Recently, they are interested in antidotes able not only to protect nerve agent-poisoned men from lethal toxic effects but also to improve their life quality by improvement of their central cognitive functions. In our study, the water maze was used to measure spatial working learning and memory in the case of tabun-induced cognitive impairment in albino Wistar rats. Antidotal treatment consisted of atropine alone or a combination of atropine with an oxime (obidoxime, trimedoxime or oxime HI-6). Our results suggest that atropine alone is not sufficient as a treatment for saving cognitive functions impaired by tabun. On the other hand, the addition of oxime to atropine contributes to improvement of cognitive performance in tabun-poisoned rats regardless of type of oxime.

Key words: Tabun; Water maze; Cognitive function; Atropine; Obidoxime; Trimedoxime; HI-6; Rats

\section{Introduction}

Organophosphates are commonly used in agriculture and in veterinary practice. Highly toxic organophosphates, called nerve agents, can be misused as chemical warfare agents (20). Potential for exposure to nerve agents, such as sarin (GB; O-isopropylmethylfluorophosphonate), tabun (GA; O-ethyldimethylamidocyanophosphate), soman (GD; O-pinacolylmethylfluorophosphonate), VX (O-ethyl-S-(2-diisopropylamino-ethyl)-methylthiophosphonate) and cyclosarin (GF; O-cyclohexylmethylfluorophosphonate) exists in the battlefield (e.g., in Iran-Iraq war), as a threat by terrorist groups (e.g., the Tokyo subway incident), or as an accident during current demilitarization efforts.

The mechanism of nerve agent-induced toxicity is based on the irreversible inhibition of acetylcholinesterase (AChE, EC 3.1.1.7) resulting in excessive acetylcholine effects within the nervous system. The peripheral cholinergic system is well understood, while the central nervous system functions research evolves. Central cholinergic systems are important in protective systems, locomotion, alertness and memory and in the regulation of a number of cyclic and periodic behaviors (27).

Nerve agent-induced cholinergic effects are usually manifested immediately following high-level exposure (20,35), nevertheless, there are numerous studies in both humans and animals showing that survivors of high-level nerve agents exposure can experience subtle but significant longterm neurological and neuropsychological outcomes that are detectable months or even years following the recovery from acute poisoning (5). In addition, behavioural alterations and impairments of cognitive functions were found following acute exposure to nerve agents in the absence of any classic signs of cholinergic toxicity $(15,31)$.

There are several behavioral tests used for the evaluation of effects of various compounds on memory functions, i.e. memory formation, consolidation and retrieval (6). Especially, a water maze is often used for its advantages and broad utilization. The water maze (WM,23) is a widely used measure of visuospatial learning that has been demonstrated to have high validity in identifying cognitive effects of various brain lesions and the effects of drugs used to treat cognitive deficits (24). Special motivation such as food and water deprivation is not required for the WM performance. In addition, rats are forced to swim in the WM. They cannot choose whether or not to move, so failure to respond is not confound (32). The place learning version with submerged platform can be used for working memory test (24). The WM can be used to measure spatial learning and memory in the case of nerve agent-induced cognitive impairment in rats because of mentioned advantages.

The rats perform cognitive tasks that require spatial learning and memory - the ability to acquire a cognitive representation of location in space and the ability to effecti- 
vely navigate the environment in the WM (32). Memory alterations appear to occur mostly in secondary memory systems and are reflected in the storage of newly acquired information $(3,12)$. It is thought that the hippocampus mediates allocentric spatial navigation (i.e., place learning), and that the prefrontal cortex is critical to acquiring the rules that govern performance in particular tasks (i.e., procedural knowledge), while the dorsomedial striatum mediates egocentric spatial orientation (i.e., response and cue learning) $(21,25)$.

The aim of our study was to evaluate the potency of currently used reactivators of $\mathrm{AChE}$ in combination with atropine to improve spatial working memory in tabun-poisoned rats.

\section{Materials and Methods}

\section{Animals}

Animals used in our experiments were male albino Wistar rats weighing 200-220 g purchased from Konarovice (Czech Republic). They were kept in an air-conditioned room and allowed to access to standard food and tap water ad libitum. The rats were divided into groups of eight animals. Handling of the experimental animals was done under the supervision of the Ethics Committee of the Medical Faculty of Charles University and Faculty of Military Health Sciences in Hradec Kralove (Czech Republic).

\section{Chemicals}

Tabun of $89.25 \%$ purity was obtained from Military Technical Institute in Brno (Czech Republic). Its purity was assayed by acidimetric titration. Oximes were synthesized at the Department of Toxicology of the Faculty of Military Health Sciences and were $98 \%$ pure. Their purity was analysed using HPLC. All other chemicals and drugs of analytical grade were obtained commercially and used without further purification.

\section{Apparatus}

The water maze consists of a black circular pool (180 $\mathrm{cm}$ in diameter, $80 \mathrm{~cm}$ high) filled to a depth of $25 \mathrm{~cm}$ with water of room temperature (Raveh, 2002). The pool was imaginarily divided into four same compartments numbered 1-4 clockwise. The black antireflective circular escape platform (15 cm diameter) was placed into compartment no. 1 or 4 (see Procedure of experiments) $20 \mathrm{~cm}$ off pool wall. The platform was sunken $2 \mathrm{~cm}$ bellow water surface, so it was not visible from rats view owing to water mirror effect. On the pool wall, immediately close to the platform, a yellow rectangle $(30 \mathrm{~cm} \mathrm{x} 40 \mathrm{~cm})$ was fixed as the spatial conditional cue (29). Its place was variable in according to the position of the platform. Another dark rectangle was randomly fixed on pool wall in different compartments (without platform) as the negative conditional cue. Round the pool, there were several stable extramaze cues in the room that the rat could use to navigate the maze.

\section{Procedure of experiments}

Animals acclimatized to the task on the two training days by being placed into the water for 60 seconds with no opportunity to escape (i.e. no platform). On zero experimental day, animals were administered with tabun (90 $\mu \mathrm{g} / \mathrm{kg}$ intramuscularly - $\left.50 \% \mathrm{LD}_{50}\right)$. One minute later, antidotal treatment was injected intramuscularly: atropine (21 $\mathrm{mg} / \mathrm{kg})$ alone; atropine $(21 \mathrm{mg} / \mathrm{kg})+$ oxime HI-6 (35 mg/kg); atropine $(21 \mathrm{mg} / \mathrm{kg})+$ obidoxime $(10.5 \mathrm{mg} / \mathrm{kg})$ or atropine $(21 \mathrm{mg} / \mathrm{kg})+$ trimedoxime $(7.5 \mathrm{mg} / \mathrm{kg})$ to the experimental groups, respectively. Oximes were administered at equieffective doses corresponding to $2 \%$ of their $\mathrm{LD}_{50}$ values. Two groups of animals were used as controls and were administered with saline instead of tabun and antidotes at the same volume $(0.1 \mathrm{ml} / 100 \mathrm{~g} \mathrm{~b}$. w. $)$. While the group named Control 1 was exposed to the same experimental conditions in the WM as experimental groups, the group called Control 2 had to solved the same trials without conditional cues. There was no intoxicated and nontreated group because of assumption of mobility alteration in animals.

WM testing was performed for eighteen days, one trial/ day. At the beginning of each trial, the rat was gently immersed in the water at the start position facing the wall of the pool. The start position was invariable for all experimental trials and took place in the compartment no. 3 . Then each animal had to search the submerged platform, the location of which was changed randomly (from compartment no. 1 to compartment no. 4). Each rat was allowed 120 seconds to escape onto the platform, if the rat failed to escape within this time, it was guided to the platform. Once the rat reached the platform, it remained there for 20 seconds to learn visual cues to the platform location. Performance on each trial was videotaped and analysed with image tracking software (TSE VideoMot2, Bad Homburg, Germany), which provided dependent measures such as latency to find the platform $(\mathrm{s})$, length of trajectory $(\mathrm{cm})$ and speed $(\mathrm{cm} / \mathrm{s})$.

\section{Statistical analyses}

Statistica'98 Edition was used for the statistical analysis of behavioral measurements. Data for behavioral tests were compared among groups by one-way analysis of variance (ANOVA). Specific comparisons were performed using Scheffé test for multiple comparisons $(1,2,28)$. The differences were considered significant when $\mathrm{P}<0.05$.

\section{Results}

The process of spatial memory formation performance in tabun-induced and treated neurotoxicity was evaluated in rats. The values of latencies, trajectories lengths and speed were measured. The recorded values of latencies and lengths of trajectories in the WM were corresponded to each other. Therefore, latency and speed data were only demonstrated in our figures. Data describing ability of rats to pass the WM within fifteen experimental trial days are recorded in 
Figures 1-3. Each of columns correspond to one experimental group and signs above the columns mean levels od statistically significant differences among groups (see legends to figures). The first column poses animals of the group Control 1 that received fysiological saline only. Those rats were already able to resolve correct WM-track on the second day. Their latencies were about 18 seconds on average. Contrary to mentioned group, animals from the group Control 2 showed appreciably worse results -35 seconds on average. They lacked the conditional cue in WM. Further, our results suggested that learning of experimental group intoxicated with tabun and consecutively treated with atropine alone is impaired in comparison with Control 1, because animals needed about two times longer latency to achieve the goal than pharmacologically unaffected animals. The negative effect of tabun and atropine is well obvious till the end of our experiment, especially from $12^{\text {th }}$ day to $18^{\text {th }}$ day. On the other hand, the treatment with antidotal combination (atropine + oxime) caused improvement of tabun-induced impairment of learning process, because measured latencies to find the hidden platform were shorter (about 25 seconds on average), even in the case of changing

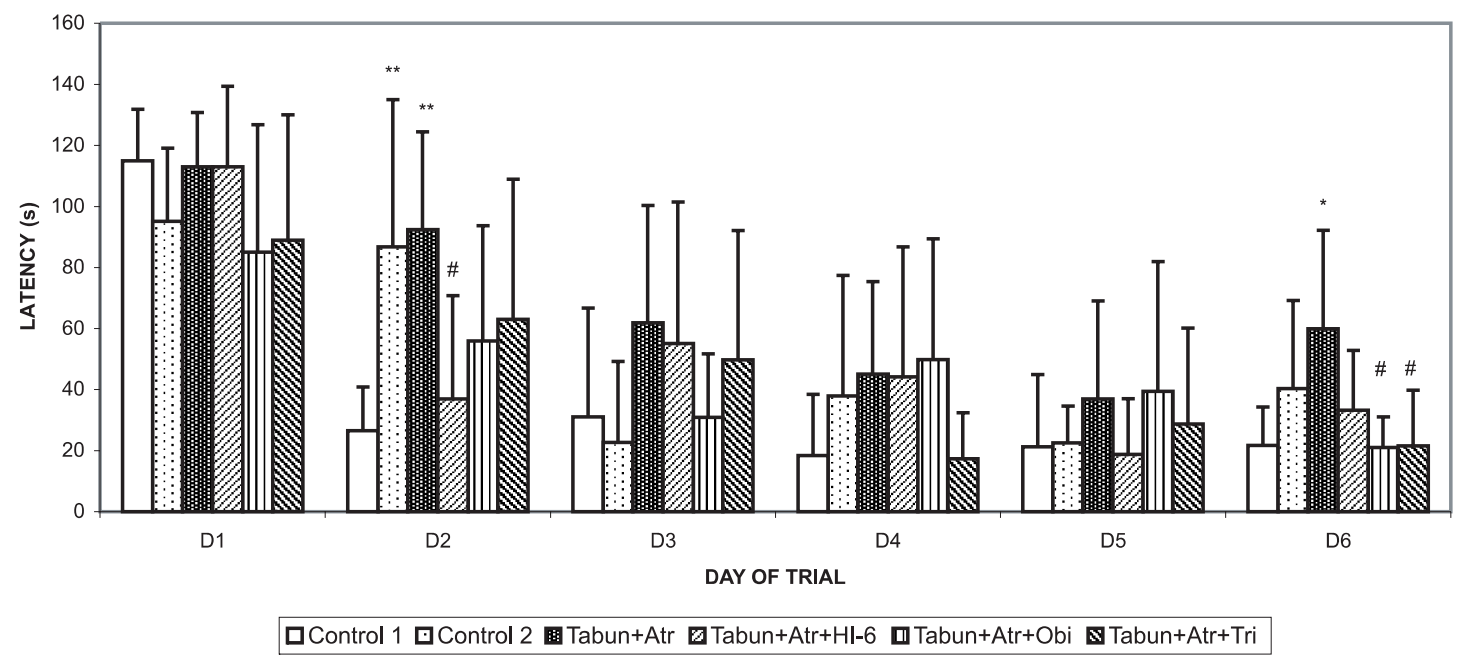

Fig. 1: The latencies of trajectories in the water maze performed by rats poisoned with tabun and treated with atropine alone or atropine in combination with oxime - day 1-6. Statistical significance to Control $1: * \mathrm{P}<0.05 ; * * \mathrm{P}<0.01 ; * * *$ $\mathrm{P}<0.001$. Statistical significance to the experimental groups treated with atropine alone: $\# \mathrm{P}<0.05 ; \# \# \# \mathrm{P}<0.001$.

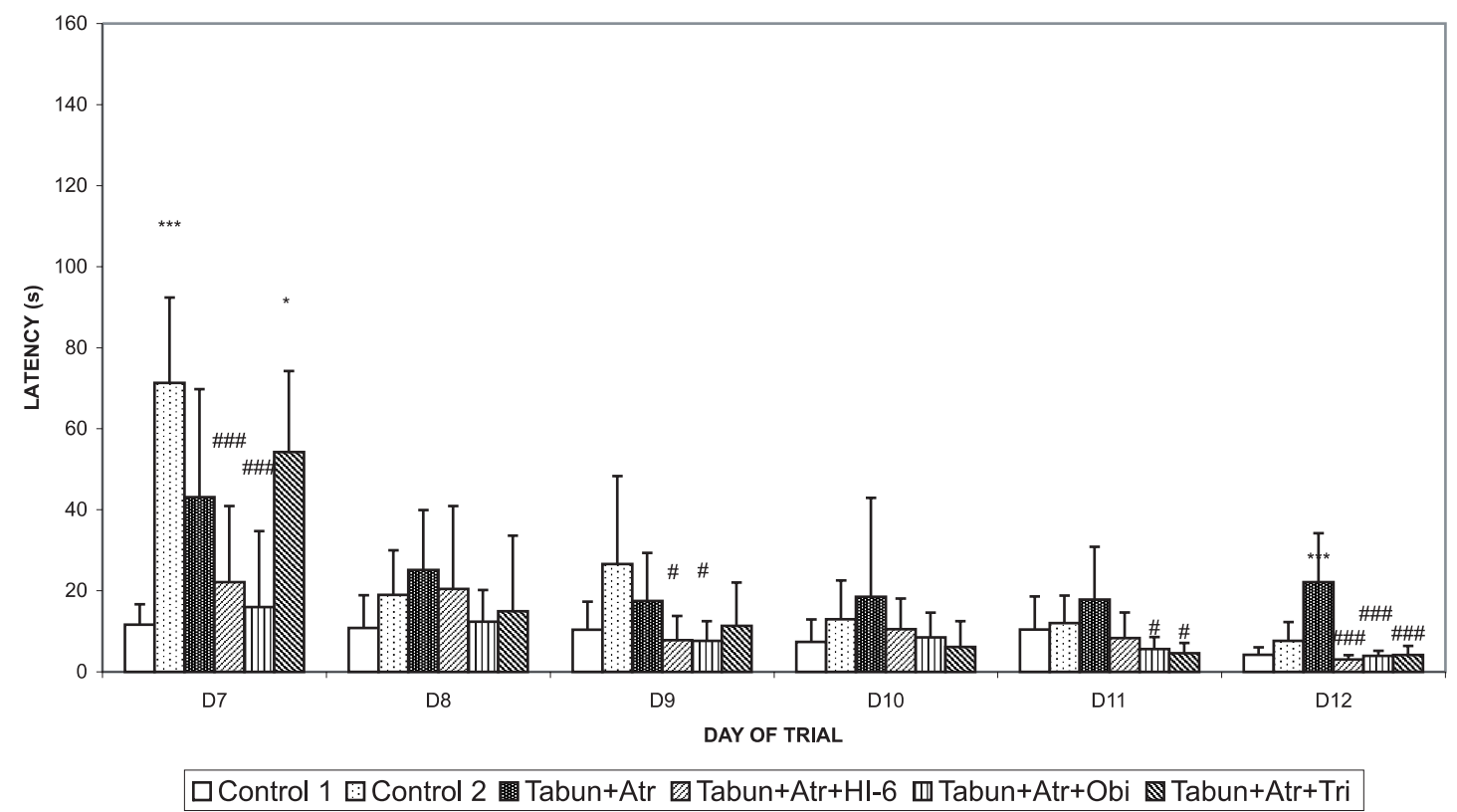

Fig. 2: The latencies of trajectories in the water maze performed by rats poisoned with tabun and treated with atropine alone or atropine in combination with oxime - day 7-12. Statistical significance: see Figure 1. 
platform location $\left(7^{\text {th }}\right.$ day and $13^{\text {th }}$ day) compared to the group of poisoned animals treated with atropine alone. The antidotal combination causes comparable data to group Control 1 in many days of trials. The performances of rats treated with antidotal combination were similar to each other regardless of the type of oximes. Animals treated with atropine and oxime HI-6 needed 20 seconds on average to pass the WM, rats treated with atropine and obidoxime about 22 seconds and animals treated with atropine and trimedoxime 29 seconds on average. There were no statistical significant differences among experimental groups treated with the antidotal mixture (atropine+oxime).

The performance alteration includes both reference memory (an initial phase of the experiment) and working memory (a trial-dependent memory during the consequential period of our experiment).

There were also speed data of swimming animals recorded. Average speed of all experimental animals was about 35 centimeters per second, slightly increasing in the course of experiment. We did not find statistical significant

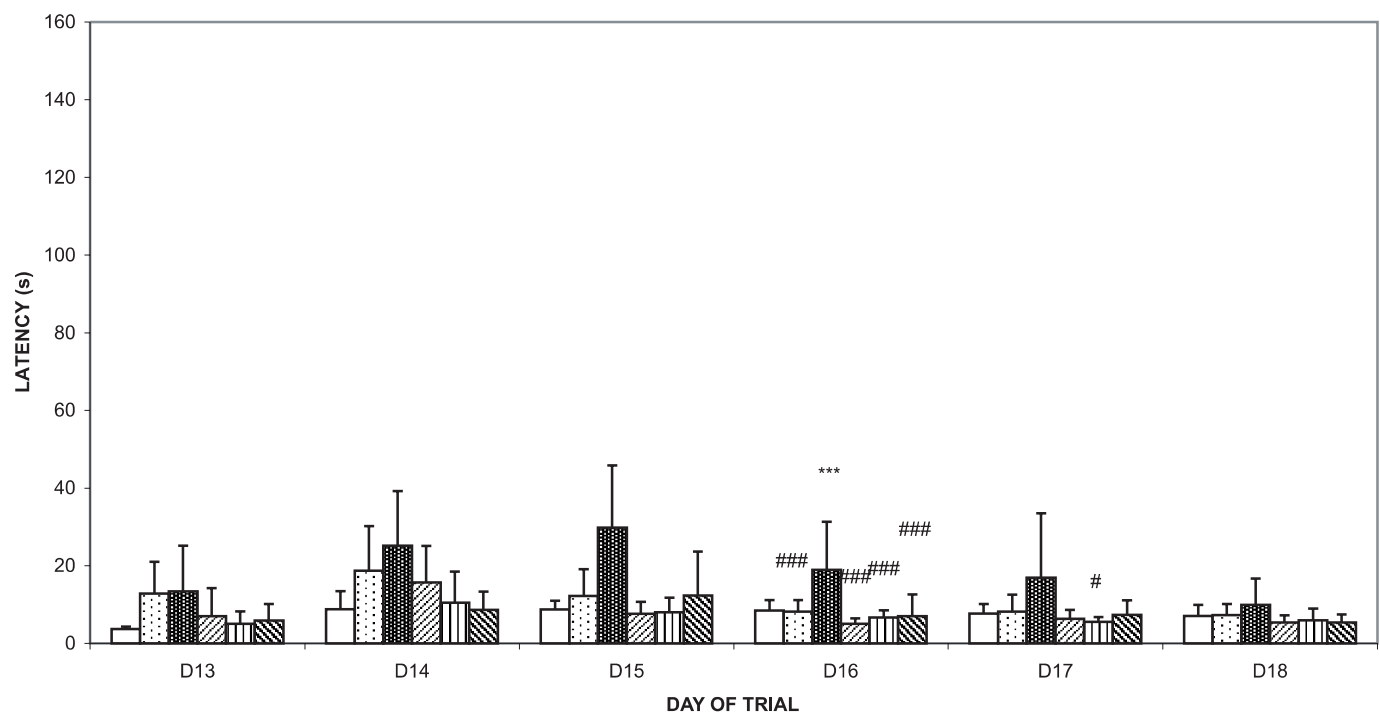

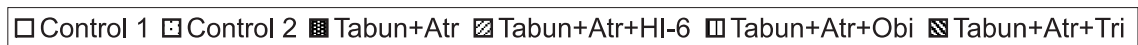

Fig. 3: The latencies of trajectories in the water maze performed by rats poisoned with tabun and treated with atropine alone or atropine in combination with oxime - day 13-18. Statistical significance: see Figure 1.

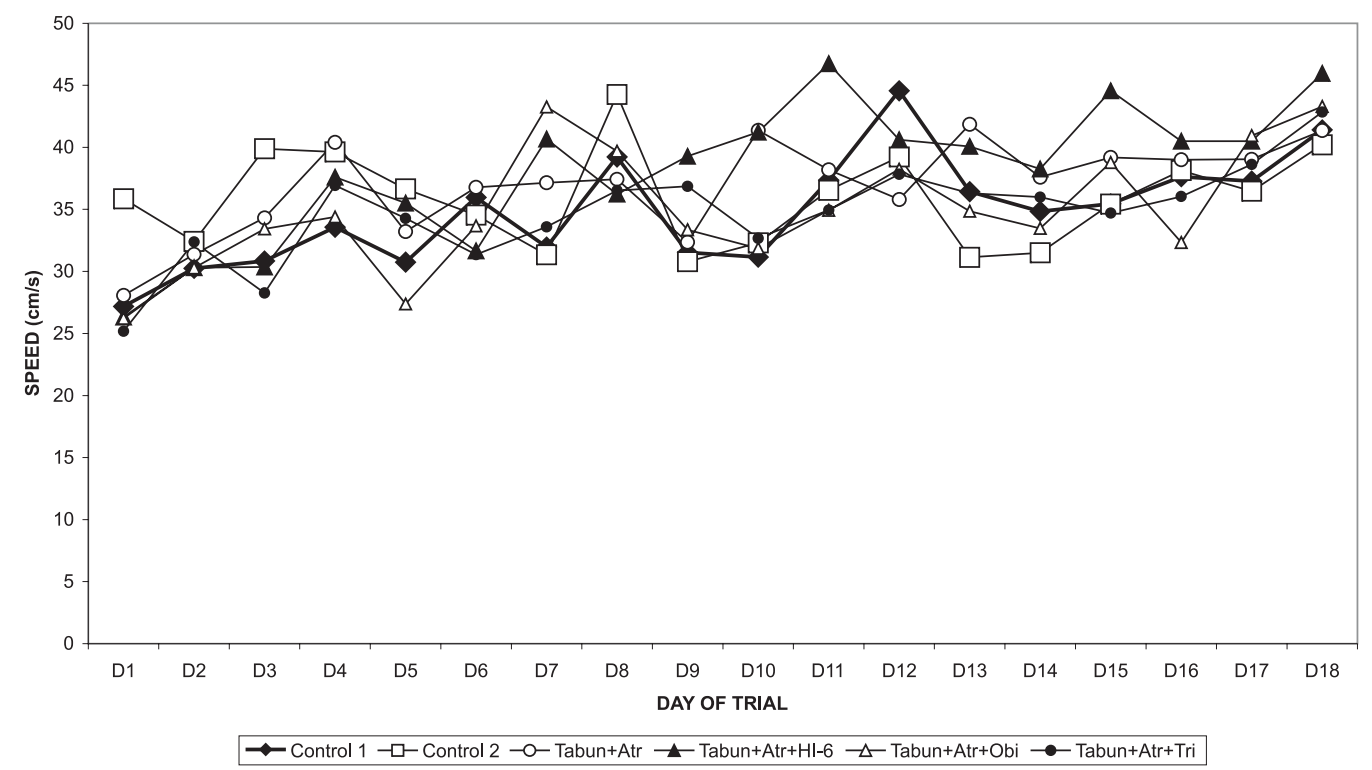

Fig. 4: The speed of rats poisoned with tabun and treated with atropine alone or atropine in combination with oxime during the performance in water maze. 
differences in speed values among experimental groups (Figure 4).

\section{Discussion}

It is known that the cholinergic system plays important role during encoding and retrieval of spatial information (30). Cholinergic modulation in hippocampus has been shown to decrease after training such as a necessary requirement for consolidation (10). It is thought that cholinergic agonist increases acetylcholine levels beyond the time testing into time when acetylcholine levels need to be dropped, thereby interfering with the consolidation process (30) and, in addition, it can cause brain damage with lesions especially in hippocampus, piriform cortex $(26,35)$ and other cortical structures (22).

The truth going for nerve agents and their ability to induce the behavioural alterations and impairments of cognitive functions following acute exposure with the absence of the classical signs of cholinergic toxicity was already mentioned $(15,31)$. The current antidotal treatment of nerve agent-induced acute poisoning includes anticholinergic drugs to antagonize the effects of acetylcholine excess at cholinergic receptor sites (34). Atropine is used to eliminate nerve agent-induced toxicity especially for its peripheral effect; its centrally acting effect is weak. That is why it can not be considered to sufficiently protect the cognitive functions of mammals in low therapeutical doses. There were also centrally acting anticholinergic drugs tested in animals for anti-nerve agent therapeutical usage (18), but just atropine remains as the main anticholinergic substance in human therapy for this while.

Moreover, atropine is coupled with oxime and this combination of atropine and oxime is considered to be a standard therapy in the case of nerve agent-induced poisoning. Generally, the reactivating efficacy of singly administerd currently used oximes is not high $(7,11)$. The reason for the low reactivating efficacy of oximes is the presence of free electron pair located on amidic nitrogen. This free electron pair makes the nucleophilic attack very difficult (17). Neveretheless, in our study, we used sublethal dose of tabun, so therapeutical doses of the antidotal mixture were able to eliminate neurotoxical effect of tabun.

The results of our study indicate that the administration of tabun treated with atropine alone causes impaired working memory performance that is believed to be trial-dependent and describes the ability of the subject to hold this trial-dependent information in memory $(9,19)$. The mentioned memory deficits were improved by the therapy containing atropine in combination with oxime.

In agreement with our assumption, output of Control 2 was worse compared to Control 1 . Working memory was impaired, if tabun-poisoned rats were treated with atropine alone. On the other hand, antidotal combination consisting of atropine and an oxime cause improvement of working memory. As recorded values of speed of animals were not statistically significant, we can exclude motoric indisposition as a cause of impaired tabun-poisoned rats performance.

From the cognitive functions point of view, we have to speculate about the role of atropine as a part of used therapy, because it was published that atropine can affect the ability to search goal platform in rodents $(4,8)$, nevertheless, atropine is considered to be integral component of antidotal treatment in the case of organophosphate poisoning $(13,14,28,33)$.

\section{Acknowledgement}

The authors express their appreciation to E. Reslova and J. Uhlirova for their skill technical assistance. The study was supported by the grant of Ministry of Defence of Czech Republic No. OBVLAJEP 20032.

\section{References}

1. Abou-Donia MB, Abdel-Rahman A, Goldstein LB, Dechkovskaia AM, Shah DU, Bullman SL, Khan WA. Sensorimotor deficits and increased brain nicotinic acetylcholine receptors folloeg exposure to chlorpyrifos and/or nice in rats. Org Tox Mech 2003;77:452-8.

2. Afifi AA, Azen SP. Statistical analysis and computer oriented approach. $2^{\text {nd }}$ ed. Academic Press, New York, 1979;442-5.

3. Bartus RT, Dean RL, Beer B, Lippa AS. The cholinergic hypothesis of geriatric memory dysfunction. Science 1989;217:408-17.

4. Boccia MM, Blake MG, Acosta GB, Baratti CM. Atropine, an anticholinergic drug, impairs memory retrieval of a high consolidated avoidance response in mice. Neurosci Lett 2003;345:97-100.

5. Brown MA, Kelley AB. Review of health consequences from high-, intermediateand low-level exposure to organophosphorus nerve agents. J Appl Toxicol 1998; 18:393-408

6. Bureš $\mathrm{J}$, Burešová $\mathrm{O}$, Huston $\mathrm{J}$ (eds). Techniques and Basic Experiments for the Study of Brain and Behavior, $1^{\text {st }}$ edn. Elsevier: Amsterdam, 1979;147-50.

7. Cabal J, Kuča K, Kassa J. Specification of the structure of oximes able to reactivate tabun-inhibited acetylcholinesterase. Pharmacol Toxicol 2004;95:81-6.

8. Day LB, Schallert T. Anticholinergic effects on acquisition of place learning in the Morris water task: spatial mapping deficit or inability to inhibit nonplace strategies? Behav Neurosci 1996;110:998-1005.

9. Frick KM, Baxter MG, Markowska AL, Olton DS, Price DL: Age-related spatia reference and working memory deficits assessed in the water maze. Neurobiol Aging 1995, 16:149-60.

10. Hasselmo M. Neuromodulation: Acetylcholine and memory consolidation. Trends Cognitive Sci 1999;3:351-9.

11. Jokanovic M, Maksimovic M, Kilibarda V, Jovanovic D, Savic D: Oxime-induced reactivation of acetylcholiesterase inhibited by phosphoramidates. Toxicol Lett 1996, 85:35.

12. Joseph JA. The putative role of free radicals in the loss of neuronal functioning in senescence. Integ Physiol Behav Sci 1992;27:216-27.

13. Kassa J, Bajgar J: Therapeutic efficacy of obidoxime or HI-6 with atropine against intoxication with some nerve agents in mice. Acta Med (Hradec Kralove) 1996, 39:27-30.

14. Kassa J, Fusek J: The influence of oxime selection on the efficacy of antidotal treatment of soman-poisoned rats. Acta Med (Hradec Kralove) 2002,45(1):19-27.

15. Kassa J, Koupilová M, Vachek J. The influence of low-level sarin inhalation exposure on spatial memory in rats. Pharmacol Biochem Behav 2001;70:175-9.

16. Kassa J, Krejcova G, Vachek J. The impairment of spatial memory following lowlevel sarin inhalation exposure and antidotal treatment in rats. Acta Medica (Hradec Kralove) 2002;45 (4):149-153.

17. Kassa J, Vachek J: A comparison of the efficacy of pyridostigmine alone and the combination of pyridostigmine with anticholinergic drugs as pharmacological pretreatment of tabun-poisoned rats and mice. Toxicology 2002;177 (2-3): $179-85$.

18. Krejcova $\mathrm{G}$ and $\mathrm{J}$ Kassa. Anticholinergic drugs - functional antidotes for the treatment of tabun intoxication. Acta Med (Hradec Kralove) 2004;47:13-18.

19. Luine VN, Richards ST, Wu VY, Beck KD. Estradiol enhances learning and memory in a spatial memory task and effects level of monoaminergic neurotransmitters. Horm Behav 1998;34:149-62.

20. Marrs TC. Organophosphate poisoning. Pharmacol Ther 1993;58:51-66.

21. McDonald RJ, White NM. Parallel information processing in the water maze: evidence for independent memory systems involving dorsal striatum and hippocampus. Behav Neurol Biol 1994;61:260-70. 
22. McLeod CG, Singer W, Harrington DG. Acute neuropathology in soman poisoned rats. Fundam Appl Toxicol 1984;5:53-8.

23. Morris RGM. Developments of a water-maze procedure for studying spatial learning in the rat. J Neurosci Methods 1984;11:47-60.

24. Myhrer T. Neurotransmitter systems involved in learning and memory in the rat: a meta-analysis based on studies of four behavioural tasks. Brain Res Rev 2003; 41:268-87.

25. Oliviera MGM, Bueno OFA, Pomarico AC, Gugliano EB. Strategies used by hippocampal- and caudate-putamen-lesioned rats in a learning task. Neurobio Learn Memory 1997;68:32-41.

26. Petras JM. Soman neurotoxicity. Fundam Appl Toxicol 1983;1:73-83.

27. Petras JM. Neurology and neuropathology of soman-induced brain injury: an overview. J Exp Anal Behav 1994;61:319-29.

28. Raveh L, Brandeis R, Gilat E, Cohen G, Alkalay D, Rabinovitz I, Sonego H Weissman BA. Anticholinergic and antiglutamatergic agents protect against soman-induced brain damage and cognitive dysfunction. Toxicol Sci 2003,75:108-16.

29. Robinson L, D Harbaran, G Riedel. Visual acuity in the water maze: sensitivity to muscarinic receptor blockade in rats and mice. Behav Brain Res 2004;151: 277-286.

30. Rogers JL, Kesner RP. Cholinergic modulation of the hippocampus during encoding and retrieval. Neurobiol Learning Memory 2003;80:332-42.

31. Sánchez-Amate MC, Flores P, Sánchez-Santed F. Effects of chlorpyrifos in the plus-maze model of anxiety. Behav Pharmacol 2001;12:285-92.

32. Shukitt-Hale B, McEwen JJ, Szprengiel A, Joseph JA. Effect of age on the radial arm water maze - test of spatial learning and memory. Neurobiol Aging 2004;25:223-29.
33. Shih TM, McDonough JH. Efficacy of biperiden and atropine as anticonvulsant treatment for organophosphorus nerve agent intoxication. Arch Toxicol 2000 $74: 165-72$

34. Taylor P. Anticholinesterase agents. In: Hardman JG, Limbird LE, editors. The Pharmacological basis of therapeutics, $9^{\text {th }}$ ed. New York: McGraw Hill, 1996 New York, pp. 161-76.

35. Tonduli LS, Testylier G, Masqueliez C, Lallement G, Monmaur P. Effects of huperzine used as pre-treatment against soman-induced seizures. Neurotoxicology 2001;22 (1):29-37

Submitted November 2005.

Accepted May 2006.

Mgr. Gabriela Kunešová, Ph.D., University of Defence,

School of Military Health Sciences,

Department of Toxicology, 50001 Hradec Králové, Czech Republic. e-mail: krejcovag@centrum.cz 